\title{
IMPROVEMENT OF TEACHER'S ORGANIZATIONAL CITIZENSHIP BEHAVIOR THROUGH TRANSFORMATIONAL LEADERSHIP DEVELOPMENT AND INTERPERSONAL COMMUNICATIONS
}

\author{
Nunung Nuryani ${ }^{a)}$, Nandang Hidayat ${ }^{a)}$, Henny Suharyati ${ }^{\left.a^{*}\right)}$ \\ a) Pakuan University, Bogor, Indonesia \\ ${ }^{*}$ Corresponding Author: henny.suharyati@unpak.ac.id
}

Article history: received 15 July 2019; revised 25 July 2019; accepted 26 August 2019

\begin{abstract}
The purpose of this study is to show Teacher's Organizational Citizenship Behavior (OCB) that can be improved by examining variables such as Transformational Leadership and Interpersonal Communication. This study uses a survey method with a correlational approach. The number of samples used was 104 people by using proportional random sampling technique. Based on the results of the study it is concluded that: (1) there is a very significant positive relationship between the Principal Transformational Leadership and Organizational Citizenship Behavior of teachers with a simple linear regression equation $\hat{Y}=99.53+0.32 \mathrm{X} 1$ and the correlation coefficient value ry. $1=0.417$. The coefficient of determination $\mathrm{r} 2 \mathrm{y} .1=0.174$ means that the Transformational Leadership (X1) contributes to the teacher's Organizational Citizenship Behavior by $17.40 \%$, (2) there is a very significant positive relationship between Interpersonal Communication with Organizational Citizenship Behavior teachers with simple linear regression equations $\hat{Y}=$ $100.44+0.29 \mathrm{X} 2$ and the correlation coefficient ry. $2=0.349$, and the coefficient of determination $\mathrm{r} 2 \mathrm{y} .2=0.116$ which means that the contribution of Interpersonal Communication (X2) to the Organizational Citizenship Behavior of the teacher is 19.60\%, (3) there is a very significant positive relationship between Transformational Leadership and Interpersonal Communication together with the Organizational Citizenship Behavior of teachers with the multiple linear regression equation $\hat{Y}=77.25+0.27 \mathrm{X} 1+0.21 \mathrm{X} 2$ and the correlation coefficient value ry. $12=0.152$. The coefficient of determination $\mathrm{r} 2 \mathrm{y} .12=0.390$ means that the Principal Transformational Leadership (X1) and Interpersonal Communication (X2) together contribute to the Organizational Citizenship Behavior of teachers (Y) by $15.20 \%$.
\end{abstract}

Keywords: transformational leadership; interpersonal communication; organizational citizenship behavior

\section{INTRODUCTION}

Education is also a human right of every Indonesian citizen who has the right to obtain quality education following his interests and talents, regardless of economic, social strata, ethnicity, religion, ethnicity, and gender. Equitable access and improving the quality of education will create Indonesian citizens with life skills, thus encouraging the growth of whole human development and civil society and modern society based on Pancasila values.

As a developing country, Indonesia needs reliable human resources who can communicate well. Verbal and visual delivery makes a significant contribution to science, technology, and art, and the welfare of the nation in general. Research shows that the optimal development of creative and innovative thinking abilities is closely related to teaching. Organizational Citizenship Behavior or abbreviated as OCB is very necessary for a non-authoritarian atmosphere when learning or self-initiative can develop because teachers put confidence in the ability of children to think and dare to express new ideas and when children are allowed to work according to their interests and needs.

Based on a preliminary survey conducted on July 17 , 2018, it was found that the results of observational data analysis of the organizational behavior of Civil Servant Teachers in Cijeruk sub-district obtained the conclusion that problems arising from the teachers included 1) constrained by problems of support, enthusiasm, and sympathetic attitude towards fellow teachers. Support sometimes appears when in certain situations. 2) The attitude to respond to a conflict between both individuals and organizations. Teachers more often ignore situations of conflict in the organization because taking care of the organization can add to the burden, 3) the teacher feels working outside working hours is a waste of time and has no impact on welfare.

Based on the above data presentation, it can be concluded that the behavior of the organization of public elementary school teachers in Cijeruk sub-district is still categorized as low. Many other factors that are thought to influence the low interpersonal communication in a school include: the performance of the principal who does not accommodate the teacher communication situation, whether there is a teacher's work motivation, whether there are a level of interpersonal communication, the managerial role of the principal in organizing the school he leads, pedagogical competence the teacher concerned, positive and conducive organizational culture in the school environment where the teacher is assigned, teacher professional competence, teacher interpersonal communication, and teacher personality competencies that are role models for students.

JA Colquit, J. Lepine, and M. Wesson [1] defines that Organizational Citizenship Behavior (OCB) is the voluntary activity of employees who can or are not rewarded but contribute to the organization by improving the overall quality where work takes place with factors the factors are a) helping coworkers, b) keeping coworkers' secrets, c) giving 
opinions for the organization's progress. d) participate, such as attending meetings and maintaining organizational information. e) be positive about the organization when in public or far from the organization.

Stephen P. Robbins and Timothy A. Judge [2] state that Organizational Citizenship Behavior (OCB) is a behavioral choice that is not part of an employee's formal work obligations, but supports the functioning of the organization effectively. The factors are 1) work exceeds expectations, 2) helping coworkers, 3) volunteering for extra work, 4) avoiding unnecessary conflict, 5) respecting rules and regulations, 6) Tolerance for work-related disorders.

Bernard M. Bass and Ronald Riggio [3] stated that transformational leadership is the leadership that stimulates and inspires followers to achieve extraordinary results and in the process of developing their leadership capacity. The indicators are 1) the leader acts as a role model or role model, 2) the leader creates a clear picture, 3) the leader stimulates people to be creative and innovative 4) the leader develops people by creating a supportive weather environment.

Ivancevich [4] defines interpersonal communication is communication that takes place from individual to individual in personal or group face-to-face meetings. The indicators are as follows: 1) facial expression, 2) take place privately, and 3) the attitude showed. This communication is direct, personal and faces to face so that facial expressions can be seen.

\section{RESEARCH METHODS}

The method used in this study is a survey method with a correlational approach. In this study, there are two independent variables namely Transformational Leadership (X1) and Interpersonal Communication (X2) and one dependent variable, Organizational Citizenship Behavior (OCB) (Y).

The constellation of problems in research is illustrated in the form of a chart as follows:

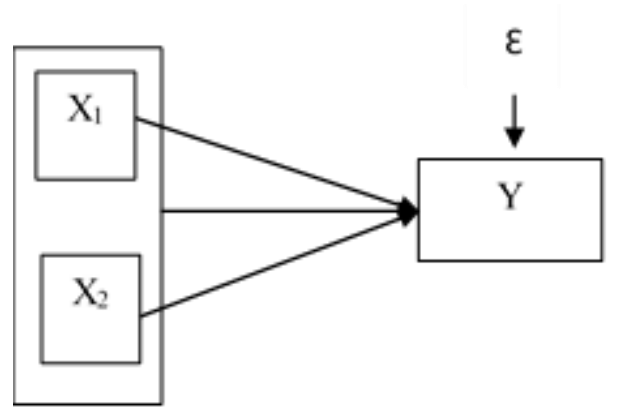

Note: $\quad \mathrm{Y}=$ Organizational Citizenship Behavior (OCB)

$\mathrm{X} 1$ = Transformational Leadership

$\mathrm{X} 2$ = Interpersonal Communication

Figure 1. Constellation The relationship between the independent variables $\left(\mathrm{X}_{1}\right)$ and $\left(\mathrm{X}_{2}\right)$ with the dependent variable $(\mathrm{Y})$.
The population in this study were 104 elementary school civil servant teachers in Cijeruk District. The technique used in sampling is simple random sampling.

The data used as the basis for the description of the results of this study are the questionnaire scores Transformational Leadership (X1), Interpersonal Communication (X2) and Organizational Citizenship Behavior $(\mathrm{OCB})(\mathrm{Y})$. the data is processed using descriptive statistical techniques.

\section{RESULTS AND DISCUSSION}

After having data collection, herewith a data description of the research:

\begin{tabular}{|c|c|c|c|c|}
\hline No. & Data Description Type & $\mathrm{Y}$ & $X_{1}$ & $\mathrm{X}_{2}$ \\
\hline 1. & Lowest score & 101 & 91 & 105 \\
\hline 2. & Highest Score & 140 & 138 & 144 \\
\hline 3. & Total Score & 13047 & 11741 & 12672 \\
\hline 4. & Standard deviation & 8,71 & 11,12 & 9,82 \\
\hline 5. & Median & 127 & 115 & 122 \\
\hline 6. & Modus & 127 & 115 & 122 \\
\hline 7. & Range & 39 & 47 & 39 \\
\hline 8. & Variance & 76,02 & 123,67 & 96,53 \\
\hline 9. & Variance & 86,03 & 131,55 & 73,28 \\
\hline
\end{tabular}

\section{Testing Requirements Analysis}

\section{Normality Test}

a. Estimation Error Normality Test (Y-Ŷ1) Regression Equation of Organizational Citizenship Behavior Teacher (Y) Variables on Transformational Leadership (X1): $\hat{\mathrm{Y}}=99.53+0.32 \mathrm{X} 1$

The requirement for estimating the error in a normal distribution is if the Lcount value <Ltable, Thus, the estimated error (Y-Ŷ1) regression equation for the Organizational Citizenship Behavior teacher (Y) for Transformational Leadership (X1) is normally distributed $($ Lcount $=0.081<0.083=\mathrm{L}$ table $)$.

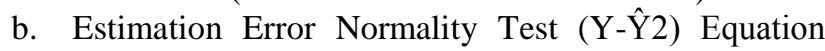
Regression Equation Organizational Citizenship Behavior Teacher (Y) for Interpersonal Communication (X2): $\hat{Y}=91.09+0.37 \mathrm{X} 2$.

The requirement for estimating the error in a normal distribution is if the Lcount value < Ltable, Thus, the estimated error ( $\mathrm{Y}-\hat{\mathrm{Y}} 2)$ regression equation variable of the Organizational Citizenship Behavior of the teacher (Y) on Interpersonal Communication (X2) is normally distributed (Lcount $=0.080<0.083=\mathrm{L}$ table $)$. A summary of the normality test using the Lilieffors test can be seen in table 2 . 
Table 2. Summary of the normality error test estimates of $\mathrm{Y}-\hat{\mathrm{Y}} 1$ and $\mathrm{Y}-\hat{\mathrm{Y}} 2$

\begin{tabular}{|c|c|c|c|c|}
\hline No & Estimated & Lcount & $\begin{array}{l}\text { Ltable } \\
(0,05 ; 103)\end{array}$ & Conclusion \\
\hline 1 & $\mathrm{Y}-\hat{\mathrm{Y}} 1$ & 0,0881 & 0,083 & Normal \\
\hline 2 & Y-रि2 & 0,080 & 0,083 & Normal \\
\hline
\end{tabular}

Note: Normal requirements: Lcount $<$ Ltable $(\alpha=0.05)$

\section{Homogeneity Test}

a.Homogeneity Test Variance Score Organizational Citizenship Behavior Teachers (Y) based on Transformational Leadership Scores (X1).

Homogeneous variance requirements are if Lcount

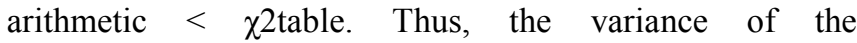
Organizational Citizenship Behavior teacher score $(\mathrm{Y})$ based on the Transformational Leadership score (X1) comes from a homogeneous population (Lcount $=19.73<50.99=\chi 2$ table).

b. Homogeneity Test Variance Score Organizational Citizenship Behavior Teacher (Y) based on Interpersonal Communication Score (X2)

Homogeneous variance requirements are if Lcount arithmetic $<\chi 2$ table. Thus, the variance of the Organizational Citizenship Behavior teacher score (Y) based on the Interpersonal Communication score (X2) comes from a homogeneous population (Lcount $=24.45<49.80=\chi^{2}$ table).

Summary of the homogeneity test of the variance of the Organizational Citizenship Behavior teacher score (Y) based on the Transformational Leadership score (X1) and Interpersonal Communication score (X2) using the Bartlett test can be seen in table 3 .

Table 3. Summary of the Variance Homogeneity Test

\begin{tabular}{|c|c|c|c|c|}
\hline No. & Grouping & $\chi_{\text {count }}^{2}$ & $\chi_{\text {table }}^{2}(\alpha=0,05)$ & Conclusion \\
\hline 1. & $\begin{array}{c}\text { Y on the } \\
\text { basis of } X_{1}\end{array}$ & 19,73 & 50,99 & $\begin{array}{c}\text { Homogeneous } \\
\text { Population }\end{array}$ \\
\hline 2. & $\begin{array}{c}\text { Y on the } \\
\text { basis of } X_{2}\end{array}$ & 24,45 & 49,80 & $\begin{array}{c}\text { Homogeneous } \\
\text { Population }\end{array}$ \\
\hline \multicolumn{6}{|c|}{ Homogeneous population requirements: ${ }$ count $_{\text {count }}<\chi_{\text {table }}^{2}$} \\
\hline
\end{tabular}

\section{Hypothesis test}

1.Relationship between Teacher's Organizational Citizenship Behavior and Self-Efficacy

The relationship between a teacher's Organizational Citizenship Behavior and Transformational Leadership is explained by testing the statistical hypothesis stated as follows:

H0: pyl $=0$ There is no relationship between teacher's Organizational Citizenship Behavior and SelfEfficacy.

H1: py1>0 There is a positive relationship between Teacher's Organizational Citizenship Behavior and SelfEfficacy.

2.The Relationship Between Interpersonal Communication and Organizational Citizenship Behavior Teachers
The relationship between Organizational Citizenship Behavior for teachers is explained by testing the statistical hypotheses stated as follows:

H0: py2 $=0$ There is no relationship between the Organizational Citizenship Behavior teacher with Interpersonal Communication

H1: py2> 0 There is a positive relationship between Teacher's Organizational Citizenship Behavior and Interpersonal Communication.

3. Analysis of the Relationship between Transformational Leadership (X1) and Interpersonal Communication (X2) together with Teacher's Organizational Citizenship Behavior (Y). The result of the correlation test can be shown on table 4 as bellow:

\begin{tabular}{|c|c|c|c|c|c|}
\hline \multirow{2}{*}{$\begin{array}{c}\text { Correlation } \\
\text { Coefficientry.12 }\end{array}$} & \multirow{2}{*}{$\mathrm{dk}$ numerator } & \multirow{2}{*}{$\begin{array}{c}\mathrm{dk} \\
\text { denominator }\end{array}$} & \multirow[b]{2}{*}{$\mathrm{F}_{\text {count }}$} & Ftable & \multirow{2}{*}{ Conclusion } \\
\hline & & & & $\alpha=0,05$ & \\
\hline 0,532 & 2 & 102 & 20,43 & 3,09 & $\begin{array}{c}\text { Very } \\
\text { Significant }\end{array}$ \\
\hline \multicolumn{6}{|c|}{$\begin{array}{c}\text { Significance level test requirements: } \\
\qquad \mathrm{F}_{\text {count }}>\mathrm{F}_{\text {table }}\end{array}$} \\
\hline
\end{tabular}

\section{Partial Correlation Test}

The results of the calculation of the partial correlation coefficient and the partial correlation significance test can be seen in Table 5.

Table 5. Calculation Results of Partial Correlation Significance Tests
\begin{tabular}{|c|c|c|c|c|}
\hline \multirow{2}{*}{ Variable control } & $\mathrm{r}_{\text {partial }}$ & $\mathrm{F}_{\text {count }}$ & $\mathrm{t}_{\text {table }}$ & \multirow{2}{*}{ Conclusion } \\
\cline { 4 - 5 } & & & $\alpha=0,05$ & \\
\hline $\mathrm{X}_{2}$ & 0,349 & 3,97 & 1,98 & Very Significant \\
\hline $\mathrm{X}_{1}$ & 0,417 & 3,44 & 1,98 & Very Significant \\
\hline \multicolumn{6}{|c|}{$\begin{array}{c}\text { Significance level test requirements: } \\
\mathrm{t}_{\text {count }}>\mathrm{t}_{\text {table }}\end{array}$} \\
\end{tabular}

1. Relationship Between the Transformational Leadership (X1) with Organizational Citizenship Behavior (Y).

The results showed that there was a positive relationship between Transformational Leadership and Organizational Citizenship Behavior. This is indicated by the correlation coefficient (ry.1) of 0.417 which is stated to be very significant. The contribution of Transformational Leadership to Organizational Citizenship Behavior is $17.40 \%$ which is stated by the coefficient of determination ( $\mathrm{r} 2 \mathrm{y} .1)$ of 0.174 . The partial correlation coefficient of Transformational Leadership (with controlled Interpersonal Communication variables) was 0.417 which was stated to be very significant.

Based on a simple linear regression equation $\hat{Y}=$ $99.53+0.32 \mathrm{X} 1$, it is predicted that every increase of one Transformational Leadership score will cause an increase of 0.34 Organizational Citizenship Behavior score to a constant of 99.53. The results of this study conclude that Transformational Leadership owned positively contributes which significantly affects Organizational Citizenship Behavior. 
The findings from other researchs prove that there is a positive and significant relationship between the organizational culture on teachers' innovativeness, transformational leadership on teachers' innovativeness and working motivation on teachers' innovativeness among teachers.[5]. Organizational culture, leadership style, and decision making, have a positive direct influence toward organizational citizenship behavior of teacher in preschool.[6]

In essence the Transformational Leadership is the leadership that can respond and change employee attitudes to commit to supporting the organization's vision, mission, and goals, as measured by instruments in the indicators, including a) the leader acts as a model or role model, b) the leader creates a clear picture, c) leaders stimulate people to be creative and innovative, d) leaders develop subordinates by creating an enabling environment.

The principal as a person who is given the task to lead the school is responsible for achieving the goals, roles, and quality of education in the school. One indicator of transformational leadership is that leaders can develop subordinate Organizational Citizenship Behavior by creating a comfortable work environment.

Transformational leadership that creates a comfortable work atmosphere can encourage interaction among fellow members. With this interaction, actions will emerge outside their main tasks such as helping, avoiding conflict and informing positive things. In a school environment, a school principal is required to have a role as the manager who is able to lead and guide the teachers to be independent in determining the best alternative in carrying out their job duties so that the role of the principal is very large for a teacher's decision making.[7] It is also shown that increasing the strength of self-efficacy and organizational citizenship behaviour together will affect the increase in teacher creativity. An increase in self-efficacy activity together with an increase in effort of organizational climate can promote teacher creativity activities [8].

\section{The Relationship Between Interpersonal Communication}

(X2) and Organizational Citizenship Behavior (Y)

The results showed that there was a positive relationship between Interpersonal Communication with Organizational Citizenship Behavior. This is indicated by the correlation coefficient (ry.2) of 0.349 which is declared significant. The contribution of Interpersonal Communication to Organizational Citizenship Behavior is $11.60 \%$ which is expressed by the coefficient of determination ( $22 \mathrm{y} .2)$ of 0.116 . The partial correlation coefficient of Interpersonal Communication (with controlled Transformational Leadership variables) is 0.349 which is stated to be significant at $\alpha=0.05$.

The pattern of the relationship between the variable of Interpersonal Communication with the variable of Organizational Citizenship Behavior is expressed by a simple linear regression equation $\hat{Y}=100.44+0.29$ X2 .

It is predicted that each increase in one score of Interpersonal Communication will cause an increase of 0.29 score in the Organizational Citizenship Behavior at constant 100,44 . The existence of a positive relationship between Interpersonal Communication with Organizational Citizenship Behavior shows that the role of Interpersonal Communication will greatly help the achievement of Organizational Citizenship Behavior. One easy way to achieve positive attitude is through communication practices. If employees are satisfied with the communication process in their organization, they will gradually obtain positive attitudes toward their communication pattern.[9]

Interpersonal communication is the process of dynamically interacting feedback between two or more personal persons who take place directly both verbally and nonverbally. The factors that influence it are 1) face to face, 2) are direct, 3) the media used, 4) the effectiveness of feedback, 5) support from others.

3.The Relationship Between Transformational Leadership (X1) and Interpersonal Communication (X2) Together with Organizational Citizenship Behavior (Y)

The results showed that there was a positive relationship between Transformational Leadership and Interpersonal Communication together with Organizational Citizenship Behavior. This is indicated by the correlation coefficient (ry.12) of 0.390 which was stated to be very significant after being tested with the test F. Contribution of Transformational Leadership and Interpersonal Communication together to Organizational Citizenship Behavior Organizations of $15.20 \%$ which is expressed by the coefficient of determination ( $\mathrm{r} 2 \mathrm{y} .12$ ) of 0.152 .

The pattern of the relationship between the Transformational Leadership variables and Interpersonal Communication together with the Organizational Citizenship Behavior variable is shown by the multiple linear regression equation $\hat{\mathrm{Y}}=\mathrm{X} 2$ with the regression coefficient which is stated to be very significant.

Organizational citizenship behavior (OCB) is an individual behavior outside the main task and obligation as a member of an organization that appears voluntarily unconditionally to support the organization. The indicators are 1) helping co-workers, 2) avoidance of conflict, 3) the workforce exceeds the minimum requirements, 4) participation for the organization's progress, 5) preserving the organization's assets and 6) informing positive things.

The achievement of the organizational citizenship behavior of every teacher if the function of interpersonal communication attached to the teacher is felt like establishing two-way communication whether using media or not. Communication that produces feedback makes a sense of emotion to help each other help and maintain the friendship of co-workers and will create positive behaviors.

\section{CONCLUSION}

The results of testing the hypothesis and the discussion described in the previous chapters can be concluded that efforts have been found to improve indicators of research variables that have a relationship with 
Organizational Citizenship Behavior teachers. The relationship between research variables can be explained as follows:

There is a positive and very significant relationship between Transformational Leadership (X1) and Organizational Citizenship Behavior of teachers (Y) as indicated by the simple linear regression equation $\hat{Y}=99.53$ $+0.32 \mathrm{X} 1$ and the correlation coefficient value ry. $1=0.417$. The coefficient of determination $\mathrm{r} 2 \mathrm{y} .1=0.174$ means that Transformational Leadership (X1) is contributing moderately to the Organizational Citizenship Behavior of the teacher by $17.40 \%$.

There is a positive and very significant relationship between the variable Interpersonal Communication (X2) with the variable Organizational Citizenship Behavior teacher $(\mathrm{Y})$. This is indicated by the simple linear regression equation $\hat{\mathrm{Y}}=100.44+0.29 \mathrm{X} 2$ and the correlation coefficient ry. $2=0.349$, and the coefficient of determination r2y.2 $=0.116$ which means that Interpersonal Communication (X2) gives a moderate contribution to Organizational Teacher Citizenship Behavior is $11.60 \%$.

There is a positive and very significant relationship between Transformational Leadership (X1) and Interpersonal Communication variable (X2) together with the teacher's Organizational Citizenship Behavior (Y) variable indicated by the multiple linear regression equation $\hat{\mathrm{Y}}=77.25+0.27 \mathrm{X} 1+0.21 \mathrm{X} 2$ and the correlation coefficient value ry. $12=0.390$. The coefficient of determination $\mathrm{r} 2 \mathrm{y} .12$ $=0.152$ means that Transformational Leadership (X1) and Interpersonal Communication (X2) together make a moderate contribution to the Organizational Citizenship Behavior of teachers (Y) of $15.20 \%$.

\section{Acknowledgment}

This Magister Thesis Research was carried out with Grant Funds from the Directorate of Community Service Research, Directorate General of Research and Development Strengthening of the Ministry of Research and Technology in accordance with the implementation year 2019 based on Funding Agreement between L2Dikti4 Office and Pakuan University Number: 110 / SP2H / LT / DRPM / 2019 March 8,2019 . Thus we thank the Kemenristekdikti for funding.

\section{REFERENCES}

[1] J.A Colquit, J.Lepine, and M. Wesson. Organitational Behavior.New York:McGraw-Hill,209.pp.448 P.472

[2] Stephen P, . Robbins dan Timothy A. Judge. Organizational Behavior; Global Edition 15 th Edition. USA: Pearson Edition (2013: h. 417)

[3] Bernand M. Bass dan Ronald Riggio. Transformational Leadership.London: Lawrence Erlbaum Associates, pubhlisers, 2006.pp 4-7

[4] Ivancevich, Konopaske, Matteson. Organizational Behavior and Management Eight Edition. New York: Mc Graw-Hill Companies Inc., 2008.
[5] Henny Suharyati, Thamrin Abdullah , Bibin Rubini, Relationship between Organizational Culture, Transformational Leadership, Working Motivation to Teacher's Innovativeness, International Journal of Managerial Studies and Research (IJMSR) Volume 4, Issue 3, March 2016, PP 29-34,

DOI: http://dx.doi.org/10.20431/2349-0349.0403005

[6] Griet Helena Laihad, Bedjo Sujanto, I Made Putrawan, Enhancing Organizational Citizenship Behavior of Teacher in Pre-School, International Journal of Managerial Studies and Research (IJMSR) Volume 4, Issue 3, March 2016, PP 25-28,

DOI: http://dx.doi.org/10.20431/2349-0349.0403004

[7] Griet Helena Laihad and Henny Suharyati, Enhanching Organizational leadership Behavior by Strengthening Leadership Style and Decision Making, International Journal of Recent Technology and Engineering (IJRTE) ISSN: 2277-3878, Volume-8 Issue-2S7, July 2019

[8] Henny Suharyati, Griet Helena Laihad, Nandang Hidayat, Susan Susan, Driving Teacher Creativity through Self Efficacy and Organizational Climate, Advances in Social Science, Education and Humanities Research, volume 253, $3^{\text {rd }}$ Asian Education Symposium (AES 2018)

[9] Nader Sheykh Al Eslami Kandlousi, Anees Janee Ali, Anahita Abdollahi, Organizational Citizenship Behavior in Concern of Communication Satisfaction: The Role of the Formal and Informal Communication, International Journal of Business and Management, Vol. 5, No. 10; October 2010, http://www.ccsenet.org/journal/index.php/ijbm/issue/ar chives 